\title{
PRODUÇÃO DE CITRATOS DE GLICEROL QUE ATUAM COMO PLATIFICANTES "VERDES" USANDO-SE A GLICERINA, EFLUENTE DA PRODUÇÃO DE BIODIESEL POR TRANSESTERIFICAÇÃO
}

\author{
D. J. L. F. de REZENDE ${ }^{1}$, R. C. Z. LOFRANO² \\ 1Universidade Federal de São João del Rei, graduando em Engenharia Química \\ ${ }^{2}$ Universidade Federal de São João del Rei, Departamento de Engenharia Química e Estatística \\ E-mail para contato: renataczlofrano@ufsj.edu.br
}

\begin{abstract}
RESUMO - Atualmente, a produção de biodiesel cresce exponencialmente, gerando cada vez mais glicerina como coproduto na produção por transesterificação. Porém, esse efluente ainda é pouco utilizado. Os ésteres de glicerol podem ser obtidos através da reação entre um agente acilante (ácidos orgânicos e anidridos) e o glicerol. O ácido cítrico pode ser encontrado em frutas cítricas e é comumente usado na indústria. Através de reações de esterificação podemos formar citratos de glicerol. Estes podem atuar como agentes plastificantes quando adicionados à composição de algum tipo de polímero, podendo substituir os ftalatos adicionados ao PVC, que são cancerígenos. Os ésteres de glicerol são considerados pouco nocivos ao homem e alguns apresentam um melhor desempenho como plastificante que o ftalato. A produção de citratos de glicerol ajudaria a solucionar o problema do excesso de glicerina e colaboraria para a produção de plastificantes "verdes", já que o ácido cítrico é uma matéria prima natural e renovável. Foram realizadas reações de esterificação empregando-se ácido cítrico e glicerol, variando-se a temperatura, a proporção estequiométrica entre os reagentes e a quantidade e o tipo de catalisador. A taxa de conversão foi obtida através de titulações ácido-base. Os altos valores de taxas de conversão demonstram que o potencial do glicerol para consumir o ácido cítrico é alto, e que a produção de citratos de glicerol é rápida e eficiente.
\end{abstract}

\section{INTRODUÇÃO}

A crescente consciência ambiental tem levado à humanidade a buscar alternativas visando-se minimizar a ação antropogênica em nosso planeta. De acordo com Goldemberg (2009), Spiro (2009) e Brown (2005) os biocombustíveis, uma vez que são obtidos de fontes renováveis, estão entre as tecnologias com maior perspectiva de crescimento nos próximos anos. O Brasil é um dos pioneiros no uso desse tipo de combustível já utilizando etanol, oriundo da fermentação da cana-de-açúcar, desde a década de 1970.

Segundo Pinto (2005) e Suarez e Meneguetti (2007), recentemente o biodiesel surgiu como uma opção viável, em termos de combustível renovável. O principal método empregado na obtenção do 
biodiesel é a reação de transesterificação de óleos vegetais usando-se álcoois na presença de um catalisador.

Essa reação resulta na formação de três moléculas de ésteres metílicos ou etílicos dos ácidos graxos que constituem o biodiesel, e uma molécula de glicerol.

Para cada $90 \mathrm{~m}^{3}$ de biodiesel, produzidos por transesterificação são gerados, aproximadamente, $10 \mathrm{~m}^{3}$ de glicerina. E, com a perspectiva de produção de elevadas quantidades desse combustível, será necessário encontrar uma utilidade para o glicerol, a fim de viabilizar a produção do biodiesel e tornar verdadeira a sua classificação como combustível sustentável.

A glicerina é um líquido claro, viscoso e incolor, de paladar adocicado e higroscópico à temperatura ambiente. Ocorre naturalmente em formas combinadas como acilglicerídeos em todos os óleos graxos de origem animal e vegetal. Para Knothe, et al. (2006), vários tipos de glicerina estão disponíveis comercialmente. Eles diferem quanto ao seu conteúdo de glicerol e em outras características como cor, odor e teor impurezas.

A chamada "glicerina loira" é normalmente utilizada para designar a glicerina oriunda dos processos de produção do biodiesel, onde a fase glicerinosa sofreu tratamento ácido para a neutralização do catalisador e remoção de ácidos graxos eventualmente formados no processo. Geralmente, esta glicerina contém aproximadamente $80 \%$ de glicerol, além de água, metanol ou etanol e sais dissolvidos.

A utilização da glicerina para a síntese de substâncias químicas de maior valor agregado é um tema de grande interesse industrial atualmente (Karinen e Krause 2006). Vários processos de conversão da glicerina em diversos produtos são conhecidos. Dentre eles, destaca-se a produção de carbonato de glicerina que é usado como solvente para vernizes, colas, cosméticos e produtos farmacêuticos e na preparação de policarbonatos. A eterificação do glicerol produz compostos de menor polaridade e viscosidade e, por conseguinte, de maior volatilidade. Isto faz com que os éteres de glicerol tenham inúmeras aplicações, sobretudo como aditivos para combustíveis e solventes, diminuindo a emissão de particulados.

São mencionados estudos (Kharchafi, et al. 2006) envolvendo reações de acetilação direta do glicerol com ácidos carboxílicos, entre eles a obtenção das acetinas que são mono, di e triacetatos do glicerol. Como esquematizado na Figura 1. Sendo elas usadas nas indústrias de explosivos, tinturas, lubrificantes, combustíveis, entre outras. A triacetina (triacetato de glicerol) é muito usada como plastificante de celulose na fabricação de filtros de cigarros. 


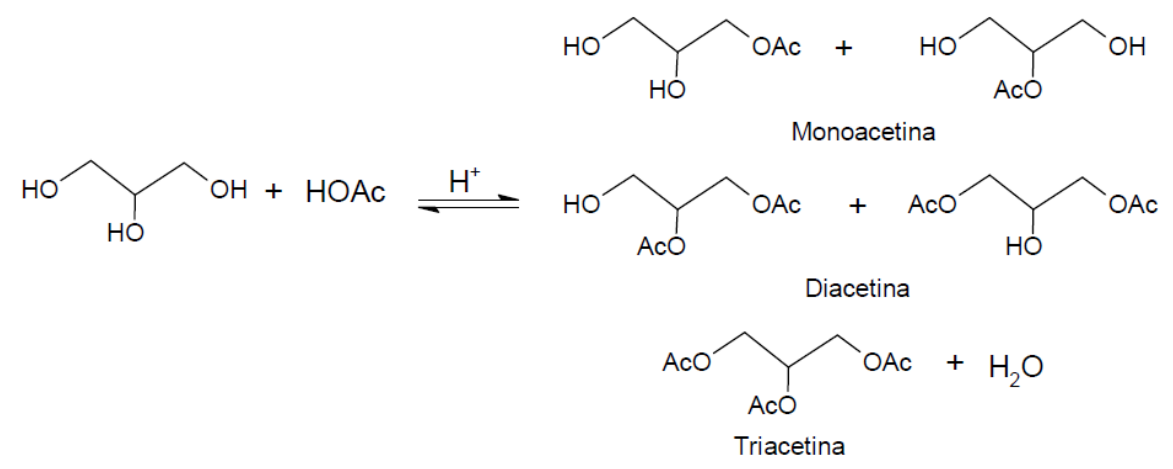

Figura 1 - Esquema ilustrativo da reação de acetilação do glicerol com ácido acético e as acetinas obtidas. (Mota, et al. 2009)

Melero, et al. (2007) estudaram a atividade e seletividade a di e triacetina na reação do glicerol com ácido acético, usando materiais mesoestruturados sulfonados como catalisador. Os resultados mostraram valores superiores a $90 \%$ de conversão do glicerol e $80 \%$ de seletividade à di e triacetina depois de $4 \mathrm{~h}$ de reação. A força ácida do ácido sulfônico foi um fator importante, afetando o desempenho catalítico desses materiais.

O ácido cítrico que pode ser encontrado em derivados do limão ou de outras frutas cítricas. É amplamente utilizado para as mais diversas aplicações, como em aditivos naturais, na indústria de alimentos, em bioquímica e como produto de limpeza ecológico, por ser livre de petróleo e biodegradável.

Segundo Maiorka, et al. (2004) o ácido cítrico ou ácido 2-hidroxi-1,2,3-propanotricarboxílico (ácido tricarboxílico) é um ácido orgânico fraco conforme mostra a Figura 2. É um sólido branco e cristalino. Sua acidez é devida aos três grupos carboxilas (-COOH) presentes em sua estrutura, sendo que cada um deles é capaz de doar um próton em soluções, cujos pKas são sucessivamente 3.15, 4.77 e 6.40. Como consequiência, forma-se o íon citrato. Os íons citratos são bons controladores de $\mathrm{pH}$ de soluções ácidas e formam diferentes citratos com íons metálicos. Han, et al (2013)<smiles>O=C(O)CC(O)(CC(=O)O)C(=O)O</smiles>

Figura 2 - Fórmula estrutural do ácido cítrico ou ácido 2-hidroxi-1,2,3-propanotricarboxílico.

Um uso alternativo da glicerina consiste na sua utilização, seja na forma pura ou de derivados, como aditivos para polímeros.

Segundo estudos de Zawadzki (2009) o poli(cloreto de vinila), PVC, vem conquistando um espaço cada vez maior no setor industrial, sendo considerado o quarto termoplástico mais consumido 


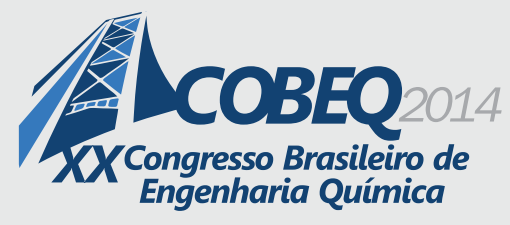

19 a 22 de outubro de 2014

Florianópolis/SC

em todo mundo, com usos em diversos segmentos do mercado, sendo a sua capacidade mundial de produção estimada em cerca de 31 milhões de toneladas/ano. O PVC apresenta várias características positivas, mas possui o inconveniente de ser muito rígido quando puro, impossibilitando a sua utilização em uma série de setores do mercado. No entanto, o PVC pode se tornar mais flexível pela adição de plastificantes, tornando o seu campo de aplicação mais amplo. 27

Por outro lado, outros polímeros também vêm despertando grande interesse industrial. Entre eles destacam-se os poliésteres termoplásticos poli(3-hidroxibutirato) (PHB) e o poli(3-hidrobutiratoco-3-hidroxivalerato) (PHVB), que podem ser utilizados como substitutos biodegradáveis dos plásticos convencionais em diversas aplicações. Estes polímeros, após seu processamento, apresentam uma alta cristalinidade, tornando-os pouco flexíveis e quebradiços, o que também restringe as suas aplicações. Assim, melhorias nas condições de processamento destes polímeros pela incorporação de plastificantes poderiam aumentar as suas perspectivas de uso comercial.

Segundo Shea (2008) um plastificante é uma substância que, adicionada a um material polimérico, modifica importantes propriedades do mesmo, tais como flexibilidade, processabilidade, maciez, fluidez, dentre outras. Isso permite a adequação dos polímeros aos mais variados processos de moldagem, incluindo injeção, extrusão ou calandragem. Os ftalatos são os plastificantes mais importantes e mais utilizados, principalmente na indústria do PVC, sendo que, dentre eles, destaca-se o ftalato de di-(2-etil-hexila), conhecido também como ftalato de dioctila (DOP). Apesar da grande compatibilidade destes ésteres com a matriz polimérica do PVC, vários estudos têm mostrado que os ftalatos apresentam certo grau de toxidez, o que torna seu uso perigoso e restrito, principalmente quando em contato com alimentos e uma possível migração do mesmo a partir das embalagens. Um estudo recente, utilizando-se cobaias submetidas ao contato direto com DOP, revelou uma grande concentração de tumores nos animais, sendo estes atribuídos ao contato do animal com o plastificante. 28 Nos seres humanos, experimentos laboratoriais comprovaram alteração hormonal e um iminente risco à saúde: o desenvolvimento anormal de fetos masculinos.26

Diante destes dados, é justificável a substituição de DOP por materiais alternativos, não tóxicos que possuem igual ou superior efeito plastificante.

Diante desse contexto, pode-se verificar que novos produtos e processos a partir do glicerol vêm sendo desenvolvidos, especialmente porque a oferta deste produto nos mercados nacional e internacional tem crescido enormemente e, o seu preço, diminuído na mesma proporção. Assim sendo, a produção de citratos de glicerol (derivados acilados do glicerol) visando-se sua aplicação como plastificantes, poderiam ajudar a solucionar o problema do excesso de glicerina. Além disso, é importante destacar que o uso do ácido cítrico/citrato nesse processo, uma vez que trata-se de uma matéria prima natural e renovável, o que torna-se um fator bastante relevante para esse estudo, pois trata-se do desenvolvimento de um processo totalmente sustentável visando-se a produção de plastificantes "verdes".

\section{OBJETIVO}

Produzir citratos de glicerol que podem ser usados como plastificantes "verdes", empregando-se 
ácido cítrico e glicerina, dando destino viável tanto ecológica quanto economicamente ao glicerol.

\section{PROCEDIMENTO EXPERIMENTAL}

\subsection{Procedimento}

De acordo com a proporção estequiométrica desejada, foram pesadas as massas do glicerol e do agente acilante que serão utilizados na reação. Os reagentes foram então adicionados ao sistema reacional e aquecidos até atingirem a temperatura na qual se deseja trabalhar. Nesse momento um catalisador $\left(\mathrm{H}_{2} \mathrm{SO}_{4}\right.$ ou $\left.\mathrm{ZnCl}_{2}\right)$ foi adicionado e do tempo de reação foi iniciado. A cada 20 minutos de reação foram retiradas duas alíquotas de $1 \mathrm{~mL}$ que foram tituladas com o indicador adequado (fenolftaleína para reações com $\mathrm{H}_{2} \mathrm{SO}_{4}$ e azul de bromotimol para reações com $\mathrm{ZnCl}_{2}$ ), dessa forma determinou-se a quantidade de agente acilante que fora convertido pela reação.

\subsection{Teste de Verificação}

As alíquotas retiradas do meio reacional a cada 20 minutos foram transferidas para um tubo de ensaio e então foram adicionadas gotas de solução aquosa de cloridrato de hidroxilamina $(5 \% \mathrm{~m} / \mathrm{m})$ e gotas de solução aquosa de $\mathrm{KOH}(5 \% \mathrm{~m} / \mathrm{m})$. A mistura resultante foi aquecida em banho-maria à aproximadamente $60^{\circ} \mathrm{C}$ durante 1 minuto. Em seguida, essa foi resfriada à temperatura ambiente. Foram adicionadas então gotas de solução de $\mathrm{HCl}\left(5 \%\right.$ v/v) e de solução de $\mathrm{FeCl}_{3}(1 \% \mathrm{~m} / \mathrm{m})$. Como resultado positivo para presença de éster no meio, a solução assumiu uma cor violeta intensa. Como resultado negativo, a solução manteve sua coloração amarelada da solução de $\mathrm{FeCl}_{3}$. Este teste qualitativo é conhecido como o "método do hidroximato férrico" e é bastante seletivo, respondendo positivamente somente quando a solução apresenta ésteres em sua composição.

\subsection{A Reação de Esterificação}

A reação de esterificação foi conduzida usando-se um sistema de refluxo constituído de balão de três bocas de $100 \mathrm{ml}$, adaptado com condensador de bolas sob refrigeração e tubo dessecante e em banho de aquecimento e sob agitação. Um termômetro foi acoplado numa das bocas, para o controle da temperatura durante a reação. As massas usadas de glicerina, ácido cítrico e catalisador $\left(\mathrm{H}_{2} \mathrm{SO}_{4}\right.$ ou $\mathrm{ZnCl}_{2}$ ) usadas foram pesadas em balança analítica e em seguida introduzidas no balão de três bocas sob constante agitação e aquecimento. Quando a temperatura reacional atingiu o valor prédeterminado, o catalisador usado foi adicionado. $\mathrm{O}$ momento da adição do catalisador foi considerado como o tempo inicial da reação. A partir da adição desse, a cada 20 minutos, $2,0 \mathrm{~mL}$ da mistura reacional foram retirados e divididos em duas alíquotas de 1,0 mL. Cada uma dessas alíquotas foi então titulada usando-se uma solução aquosa padronizada 1,0 mol L-1 de $\mathrm{NaOH}$. Como indicadores foram usados fenolftaleína para reações que utilizaram $\mathrm{H}_{2} \mathrm{SO}_{4} \mathrm{e}$ azul de bromotimol para reações com $\mathrm{ZnCl}_{2}$. $\mathrm{O}$ volume de solução básica ou titulante determinado em cada titulação foi utilizado no cálculo da taxa de conversão do agente acilante nos produtos da reação.

\section{RESULTADOS}


Para realizar a reação entre o glicerol PA e o ácido cítrico, foi preciso no primeiro momento estudar a solubilidade do ácido no álcool. A Tabela 1 mostra a solubilidade do ácido cítrico no glicerol em diferentes temperaturas.

Tabela 1 - Solubilidade do ácido cítrico em glicerol em diferentes temperaturas.

\begin{tabular}{ccc}
\hline $\begin{array}{c}\text { Proporção } \\
\text { ácido:glicerol P.A. }\end{array}$ & $\begin{array}{c}\text { Temperatura } \\
\left({ }^{\circ} \mathbf{C}\right)\end{array}$ & Solubilidade \\
\hline $\mathbf{1 : 5}$ & 25 & Insolúvel \\
$\mathbf{1 : 5}$ & 60 & Insolúvel \\
$\mathbf{1 : 5}$ & 100 & Insolúvel \\
$\mathbf{1 : 5}$ & 110 & Solúvel \\
$\mathbf{1 : 5}$ & 120 & Solúvel \\
\hline
\end{tabular}

O uso da proporção 1:5 ácido:glicerol se deve ao fato do glicerol estar em excesso e atuar também como solvente na reação. Após os estudos de solubilidade, temperaturas de aproximadamente $110^{\circ} \mathrm{C}$ foram utilizadas nos experimentos pois foi a temperatura mínima necessária para solubilizar o todo o ácido cítrico no glicerol. Estudou-se a reação utilizando como catalisadores tanto o ácido sulfúrico quanto o cloreto de zinco (um ácido de Lewis). A Tabela 2 mostra a taxa de conversão das reações estudadas.

Tabela 2 - Conversão de ácido cítrico e glicerol P.A. em ésteres em diferentes condições reacionais.

\begin{tabular}{cccccc}
\hline $\begin{array}{c}\text { Proporção } \\
\text { ácido: glicerol } \\
\text { P.A. }\end{array}$ & $\begin{array}{c}\text { Temperatura } \\
\left({ }^{\circ} \mathbf{C}\right)\end{array}$ & $\begin{array}{c}\text { Tipo de } \\
\text { catalisador }\end{array}$ & $\begin{array}{c}\text { Mol } \\
\text { catalisador } \\
\text { /mol ácido } \\
(\boldsymbol{\%})\end{array}$ & $\begin{array}{c}\text { Teste de } \\
\text { verificação }\end{array}$ & $\begin{array}{c}\text { Conversão } \\
(\boldsymbol{\%})\end{array}$ \\
\hline $\mathbf{1 : 5}$ & 115 & $\mathrm{H}_{2} \mathrm{SO}_{4}$ & 18,7 & Positivo & 98,4 \\
$\mathbf{1 : 5}$ & 115 & $\mathrm{H}_{2} \mathrm{SO}_{4}$ & 4,69 & Positivo & 92,0 \\
$\mathbf{1 : 5}$ & 115 & $\mathrm{ZnCl}_{2}$ & 3,70 & Positivo & 64,8 \\
$\mathbf{1 : 5}$ & 115 & $\mathrm{ZnCl}_{2}$ & 1,00 & Positivo & 64,2 \\
\hline
\end{tabular}

Em todas as reações observadas, o teste de verificação indicou a formação de ésteres nos primeiros 20 minutos após a adição de catalisador (Tabela 2 e Figura 3). Nas reações em que o ácido sulfúrico foi utilizado como catalisador, observou-se que ainda é necessário ajustar a quantidade ideal de desse catalisador a ser utilizado, uma vez que pelas taxas de conversão obtidas em relação às quantidades de catalisador usadas, pode-ser verificar que se aumentarmos um pouco a quantidade desse, talvez tenhamos uma melhora na taxa de conversão (Tabela 2). Entretanto o uso do $\mathrm{ZnCl}_{2} \mathrm{em}$ diferentes quantidades 3,7 e 1,00 \% não apresentou significativa diferença nos valores de taxas de conversão obtidas 64,8 e 64,2\% respectivamente. O que indica que para esse catalisador, já podemos definir uma quantidade mínima para seu uso. Todavia, estudos serão realizados visando-se otimizar a quantidade de $\mathrm{ZnCl}_{2}$ e os valores das taxas de conversão obtidos. 


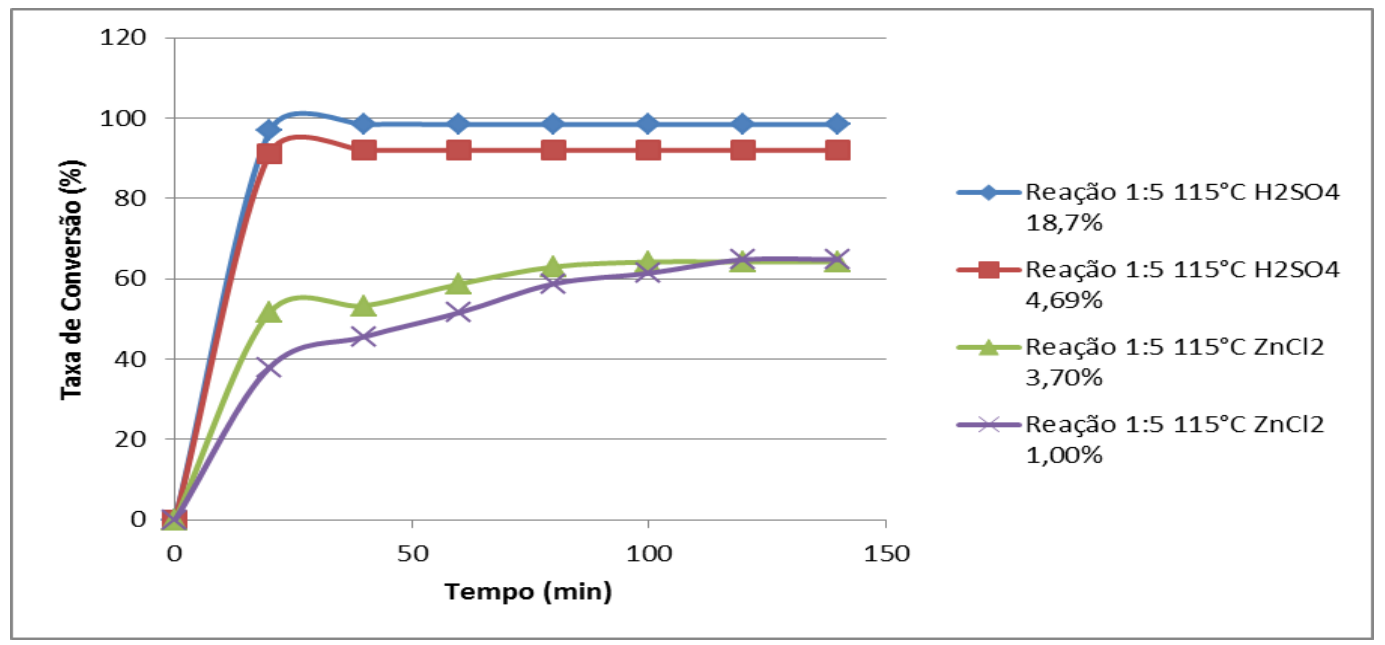

Figura 3 - Gráficos referentes às taxas de conversão das reações entre ácido cítrico e glicerol P. A. e catalisador usando-se diferentes condições.

Analisando-se a Figura 3 acima podemos perceber que todas as reações realizadas seguem o mesmos padrão reacional. Ocorre um máximo de conversão nos primeiros 20 minutos de reação e depois essa praticamente se estabiliza.

Outros estudos foram realizados usando-se as mesmas condições reacionais, alterando-se apenas o glicerol P. A. para "glicerina loira", proveniente da produção do biodiesel por transesterificação. Nesses estudos usando-se $\mathrm{ZnCl}_{2}$ como catalisador, podemos observar que a reação ocorreu de forma mais lenta. Não foi observado o mesmo perfil reacional do glicerol P. A., ou seja, a presença de algum pico, e sim de uma inclinação (Figura 4).

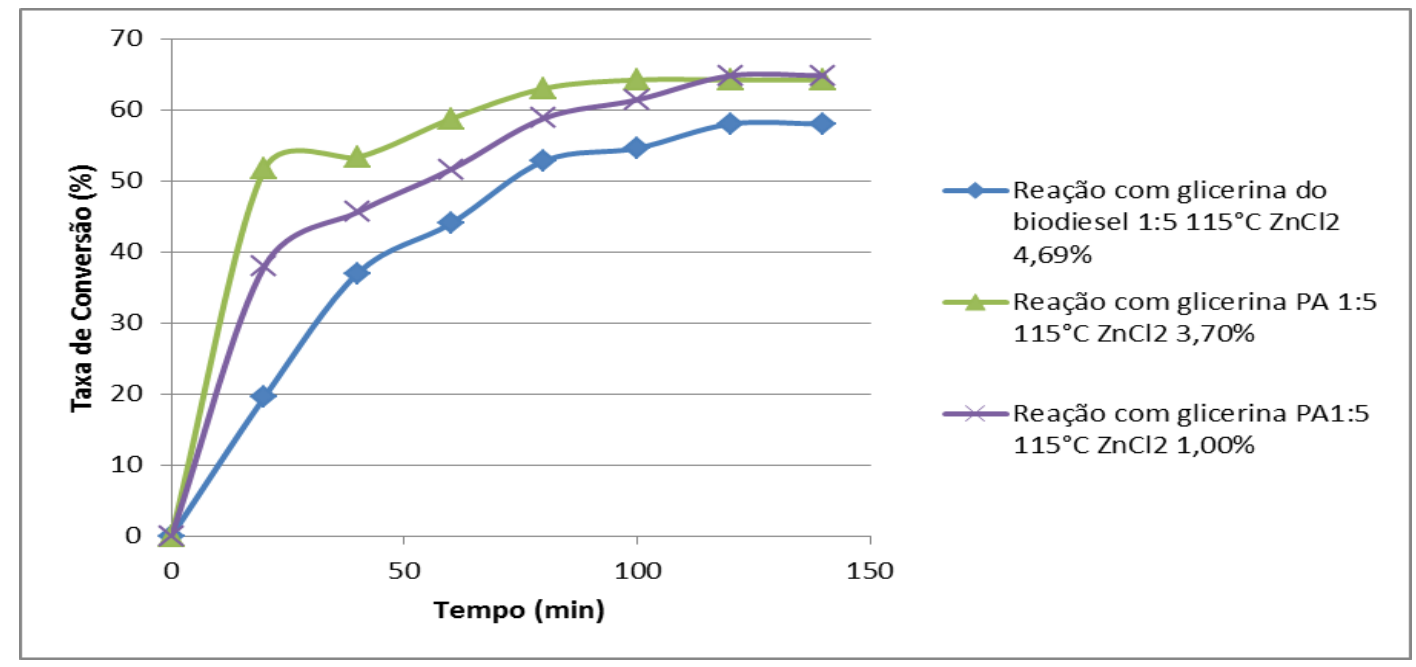

Figura 4 - Gráficos referentes às taxas de conversão das reações entre ácido cítrico e "glicerina loira" e catalisador usando-se diferentes condições. 


\section{DISPOSIÇÕES FINAIS}

Através dos estudos realizados percebeu-se que a reação entre ácido cítrico e glicerol é viável, pois as taxas de conversão mostram-se elevadas e o tempo de reação é baixo, ou seja trata-se de uma reação rápida e eficiente. Assim sendo, torna-se possível mais uma aplicação à glicerina efluente do biodiesel, produzindo-se plastificantes à partir de fontes totalmente renováveis.

Vale ressaltar que outros estudos ainda serão realizados visando-se conhecer melhor a reação o que nos permitirá aperfeiçoar-la, obtendo-se assim taxas de conversão ainda mais elevadas. Ou ainda diminuindo o tempo reacional.

\section{REFERÊNCIAS}

GOLDEMBERG, J.; Quim. Nova 2009 32, 582.

SPIRO, T. G.; Química Ambiental, 2a ed., Pearson Prentice Hall: São Paulo, 2009, 164.

BROWN, T. L.; Química, A Ciência Central, Pearson Prentice Hall: São Paulo, 2005, 659.

PINTO, A. C. et al ; J. Braz Chem. Soc. 2005, 16, 1313.

SUAREZ, P. A. Z.; MENEGUETTI, S. M. P.; Quim. Nova 2007, 30, 2068.

MORRISON, R; BOYD, R.; Química Orgânica. 14a ed., Fundação Calouste Gulbenkian: Lisboa, 2005,Cap. 20 e 33.

KNOTHE, G.; GERPEN, J. V.; KRAHL, J.; RAMOS, L. P.; Manual do Biodiesel, Edgard Blücher: São Paulo, 2006, Cap. 9.

KARINEN, R. S.; KRAUSE, A. O. I.; Applied Catalysis A: General 2006, 306, 128.

KHARCHAFI, G.; JÉRÔME, F.; DOUILEZ, J. P.; BARRAULT, J.; Green Chem. 2006, 8, 710.

MOTA, C. J. A.; DA SILVA, C. X. A.; GOLÇELVES, V. L. C.; Quim. Nova 2009, 32, 639.

MELERO, J. A.; VAN GRIEKEN, R.; MORALES, G.; PANIAGUA, M.; Energy \& Fuel 2007, 21, 1782.

MAIORKA, A.; SANTIN, A.M.E.; BORGES, S.A.; OPALINSKI, M.; Silva, A.V.F. Archives of Veterinary Science 2004,. 9(1), 31.

HAN, Q. et al; Materials Letters 2013, 95, 9.

ZAWADZKI, S. F.; Dissertação de Mestrado, Universidade Federal do Paraná, Brasil, 2009.

SHEA, K. M.; American Academy of Pediatrics. 2008, 111, 1467.

YANGA, H., et al; Bioresource Technology. 2013, 127, 248.

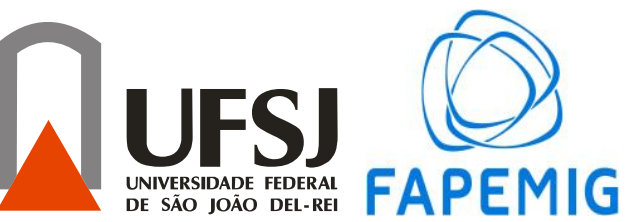

